TI 2014-099/VIII

Tinbergen Institute Discussion Paper

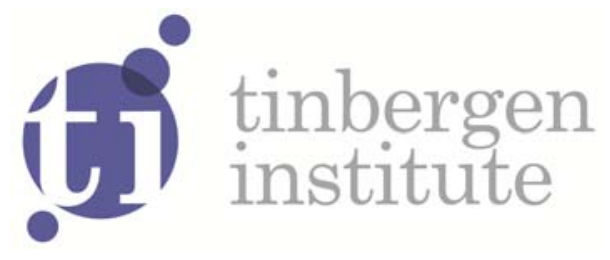

\title{
Price Differentiation and Discrimination in Transport Networks
}

Adriaan Hendrik van der Weijde

Faculty of Economics and Business Administration, VU University Amsterdam, and Tinbergen Institute. 
Tinbergen Institute is the graduate school and research institute in economics of Erasmus University Rotterdam, the University of Amsterdam and VU University Amsterdam.

More TI discussion papers can be downloaded at http://www.tinbergen.nl

Tinbergen Institute has two locations:

Tinbergen Institute Amsterdam

Gustav Mahlerplein 117

1082 MS Amsterdam

The Netherlands

Tel.: +31(0)205251600

Tinbergen Institute Rotterdam

Burg. Oudlaan 50

3062 PA Rotterdam

The Netherlands

Tel.: +31(0)10 4088900

Fax: $+31(0) 104089031$

Duisenberg school of finance is a collaboration of the Dutch financial sector and universities, with the ambition to support innovative research and offer top quality academic education in core areas of finance.

DSF research papers can be downloaded at: http://www.dsf.nl/

Duisenberg school of finance

Gustav Mahlerplein 117

1082 MS Amsterdam

The Netherlands

Tel.: +31(0)20 5258579 


\title{
Price differentiation and discrimination in transport networks*
}

\author{
Adriaan Hendrik van der Weijde ${ }^{\dagger}$ \\ Department of Spatial Economics, Vrije Universiteit Amsterdam, De Boelelaan 1105, $1081 \mathrm{HV}$ \\ Amsterdam, The Netherlands \\ Tinbergen Instute, Gustav Mahlerplein 117, 1082MS Amsterdam, The Netherlands.
}

\begin{abstract}
This paper analyzes the effects of price differentiation and discrimination by a monopolistic transport operator, which sets fares in a congestible network. Using three models, with different spatial structures, we describe the operator's optimal strategies in an unregulated market, a market where price differentiation is not allowed (i.e., ticket prices must be the same for all users), and a market where price discrimination is illegal (i.e., ticket prices must only differ with the marginal external costs of users), and analyze the welfare effects of uniform and nondiscriminatory pricing policies. The three models allow us to consider three different forms of price differentiation and discrimination in networks: by user class, by origin-destination pair, and by route.

We generalize the existing literature, in which groups usually only differ in their value of time, and hence, there is no distinction between differentiation and discrimination. In our models, users may also have different marginal external costs; we show how these two differences interact. We also show how non-differentiated and non-discriminatory policies may increase or decrease welfare, and that non-discrimination can be worse than non-differentiation. The network models show that results obtained for a single-link network can be generalized to a situation where operators price-discriminate or differentiate based on users' origins and destinations, but not directly to a situation in which differentiation is based on route choices.
\end{abstract}

\section{Introduction}

This paper investigates the effects of allowing or disallowing transport operators to charge different users different tolls or fares. Charging different tolls or fares to different users is common practice in many transportation markets. This differentiation in prices is particularly interesting in the context of transportation, as, unlike in markets for most consumer goods, there usually consumption externalities associated with travel. Moreover, these externalities are not usually symmetric: the

*Financial support from ERC Advanced Grant \#246969 (OPTION) is gratefully acknowledged. The author thanks Vincent van den Berg, Achim Czerny, Hugo Silva and Erik Verhoef for their helpful comments and suggestions.

${ }^{\dagger}$ Tel.: +31 2059 86106. E-mail: h.vander.weijde@vu.nl 
congestion externality imposed by, for instance, a passenger car driver on a truck driver using the same road at the same time is unlikely to be the same as the externality imposed by the truck on the car driver. There may also be other reasons, apart from these externalities, for different users to have different marginal costs: e.g., some types of vehicles cause more road damage than others, drivers of cars outfitted with transponders are easier to toll than drivers who pay in cash, and in air travel, the weight of passengers and their luggage directly affects fuel consumption. Travel products are also difficult to resell, and different groups of users can often be easily distinguished, which makes is easy to differentiate prices.

It is not surprising, therefore, that many existing studies look at these issues in the context of transportation markets, both empirically and theoretically. Adachi (2005), for instance, formulates a linear model with consumption externalities, in which all users have the same marginal external costs, but different marginal private costs. In this linear model, monopolistic third-degree price differentiation does not change output, but can increase welfare if it improves the composition of users. Nocke et al. (2011) show how a monopolist can use advance-purchase discounts to pricediscriminate. Closest this paper, Czerny and Zhang (2014), in the context of air travel, use a model with general demand- and cost functions, in which different users have different values of time, but the same marginal external cost. They conclude that ticket-price discrimination can increase welfare, even if it reduces the total number of travelers. If all users have the same value of time, and their inverse demand- and cost curves are linear, price discrimination does not change this total number of travelers.

This paper aims to make three contributions to this literature. First of all, we will consider a situation in which users do not only have different values of time (and thus, different marginal costs), but al so different marginal external costs. This difference can, for instance, arise if vehicles have different sizes (e.g. trucks and cars), and thus, impose different congestion externalities on other users. This is well-established in the empirical literature (see e.g., Al-Kaisy et al., 2002), but not usually incorporated in studies on price discrimination.

Secondly, these differences in marginal external costs also allow us to distinguish between two situations in which different users are charged different fares or tolls. Rather than calling all instances where different users or user groups are charged different prices for the same product 'price discrimination', we will distinguish price discrimination and price differentiation, and examine both pricing regimes separately. If $I$ is the set of all user classes (or individual users if each class only has one member) and $f_{i}$ the toll or fare charged to a particular class $i$, we say that price differentiation occurs if

$$
\exists\{i, j\} \in I^{2} f_{i} \neq f_{j}
$$

If, in addition $c_{i}$ is the cost of travel (not including tolls) faced by user class $i$ and $n_{i}$ the number of users from class $i$ that travel, and assuming that the marginal costs of transport provision are independent of the user class, price discrimination occurs when

$$
\exists\{i, j\} \in I^{2} f_{i}-\sum_{k}\left(\partial c_{k} / \partial n_{i}\right) n_{k} \neq f_{j}-\sum_{k}\left(\partial c_{k} / \partial n_{j}\right) n_{k}
$$

In other words, price differentiation occurs if different user groups are charged different tolls or fares, and price discrimination occurs if groups are charged different tolls based only on their demand structures, rather than costs. This definition of price discrimination (Eq. 2) is common in the microeconomics and industrial organization literature ${ }^{1}$ (see, e.g., Stigler, 1986; Tirole, 1988; Stole,

\footnotetext{
${ }^{1}$ There, it is usually a difference in marginal production costs that leads to differentiation without discrimination, but the idea is the same.
} 


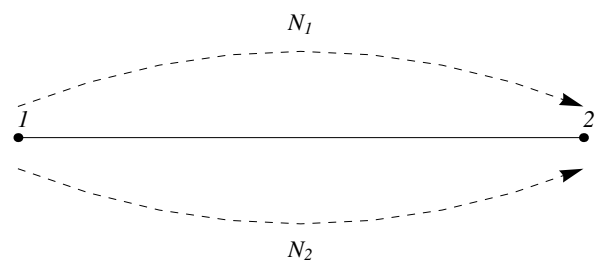

Figure 1: Model 1: user classes

2007; Verboven, 2008); in the more recent transportation literature (e.g. Czerny and Zhang, 2014), on the other hand 'price discrimination' is often defined as in Eq. 1: what we call 'differentiation'.2 If there are no external costs associated with consumption, or if the external costs are the same regardless of which consumer buys the product, the two definitions are the same. In transportation markets, however, users often have different external costs (e.g., consider the example of truck- and car drivers mentioned above). Hence, price differentiation can occur without discrimination; indeed, disallowing differentiation can lead to discrimination. We therefore think that, in our context, it is particularly important to make a distinction between the two. Price differentiation occurs often, and can easily be justified on the basis of 'fairness'; trucks, for instance, are often charged higher tolls than passenger cars. Price discrimination, on the other hand, is often perceived as 'unfair', since it differentiates between users only on the basis of their willingness to pay, not on a difference in costs. Nevertheless, it is also practiced in transportation markets, e.g., in the form of discounts for users above a certain age.

Thirdly, we explicitly consider the networked nature of transportation markets. Most studies look at one market in isolation. This allows for the analysis of discrimination between users or user classes, and often produces tractable, interpretable results. For this reason, we too will start our analysis with a simple single-market model, in which several user classes travel on one link, and the operator discriminates and/or differentiates between these classes. In a network, however, users from different origins travel to different destinations. When deciding what to charge for use of a link, an operator can then also differentiate and/or discriminate based on users' origin-destination (OD) pairs. If there are multiple links connecting two nodes, an operator could also differentiate by route. These last two types of differentiation and discrimination can only be analyzed using a network model.

A model that combines all these forms of price discrimination and differentiation would not be tractable, so we examine three separate models. In the first (Fig. 1), one congestible link is shared by two classes of users, each with its own inverse demand function. If the monopolistic operator is not allowed to differentiate between the two classes, it sets one fare $f$, which is paid by all users. If it can differentiate, it sets two fares, $f_{1}$ and $f_{2}$, which are paid only by the users from the first and second class, respectively. If differentiation is allowed, but discrimination is not, these two fares can differ only as much as the marginal costs of the two user groups differ. In transport markets, this type of price differentiation may be achieved by, for instance, offering a reduced fare for senior travelers, or charging cars and trucks different road prices.

In the second model (Fig. 2), we include serial network effects, and consider price discrimination and differentiation by OD-pair. There are now three nodes, two links in series connecting them,

\footnotetext{
${ }^{2}$ This terminology is not new: see, for example, Chen and Schwartz (2013)
} 


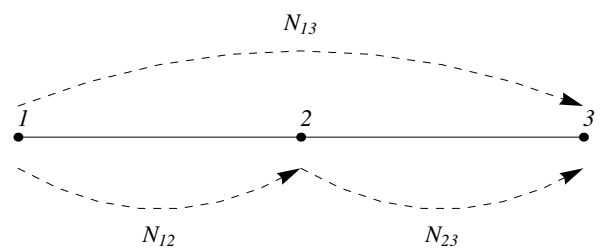

Figure 2: Model 2: OD-pairs

and three groups of users: two groups short-distance travelers traveling from node 1 to node 2 and from node 2 to 3 , and long-distance travelers traveling from 1 to 3 ; each has its own inverse demand function. Congestion functions may differ between links, and long-distance travelers incur congestion costs on both links. Hence, while in the first model two groups of users impose congestion externalities on each other, this model has three groups, each of which imposes a congestion externality on some, but not all, others. If the operator can differentiate between OD-pairs, it sets three fares, one for each class of users. If the long-distance travelers pay more than the sum of the two short-distance fares, there is differentiation on at least one of the two links. ${ }^{3}$ If the operator cannot differentiate, all users pay the same for use of each link, and hence, long-distance fares are equal to the sum of the two short-distance fares. Again, if differentiation is allowed, but discrimination is not, the operator still sets three fares, but any difference between the long-distance fare and the sum of the two short-distance fares has to be related to marginal cost differences. This type of differentiation is similar to what is sometimes called 'price discrimination by bundling' (Adams and Yellen, 1976; Zhang and Czerny, 2012). Although it is common in public transport markets markets (the ticket price for travel from $\mathrm{A}$ to $\mathrm{C}$ via $\mathrm{B}$ is often different from the sum of the prices for travel from B to C and B to C), it is certainly not used everywhere; road prices, for instance, are often additive.

In the third model (Fig. 3), we look at the effects of parallelity in networks. There is only one class of users, but two parallel links, and hence, two routes, with different congestion functions. Here, we consider price differentiation by route. In contrast to the previous two models, users only impose congestion externalities on other users taking the same route; however, the choices they make still affect all users through the inverse demand function. If the operator can differentiate between routes, it sets two fares $f_{1}$ and $f_{2}$, to be paid by $N_{1}$ users taking the first route, and $N_{2}$ users taking the second, respectively. If it cannot differentiate, it sets one fare $f$, which is paid by all users, regardless of their route choice. If it can differentiate but not discriminate, $f_{1}$ and $f_{2}$ differ only with the marginal cost functions of the two user classes. ${ }^{4}$ This type of price differentiation (or its absence) is also present in many public transport markets: one ticket for travel between two cities may, or may not be, valid on a number of routes.

Together, these three models encompass the range of options for price differentiation and discrimination in public transport markets. They are, to some extent, variations on the same theme,

\footnotetext{
${ }^{3}$ I.e., the 'product', here, is travel between two nodes. Since there are three nodes, and two links connecting them, there are two products. One could formulate a model with four fares (two for each link, one for long-distance travelers, and one for short-distance travelers). However, since long-distance travelers would always pay the sum of the two long-distance fares, only this total long-distance fare would be unique; the individual long-distance fares themselves would arbitrary, given their total. We therefore only use the total long-distance fare.

${ }^{4}$ Again, the 'product' is defined as travel between two nodes.
} 


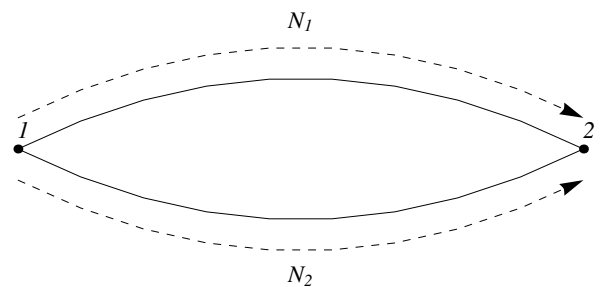

Figure 3: Model 3: routes

and could be incorporated in one, generalized network model. Treating them separately, however, allows us to consider the different effects of price differentiation and discrimination in isolation. In each of the models, we derive the first-best socially optimal fares, and three sets of private fares: one as they would be set by an unrestricted monopolist, one where the monopolist is not allowed to differentiate, and one where the monopolist is allowed to differentiate, but cannot discriminate. We then compare these outcomes, to see if and when price differentiation and/or discrimination can improve welfare. As far as possible, we use general cost- and demand functions; in some cases, we need to impose linearity to produce meaningful results.

Naturally, we can not consider all possible forms of differentiation and discrimination in this paper. Specifically, in line with most of the existing literature, we limit the scope of our analysis in four ways. First, we restrict ourselves to third-degree discrimination (sometimes called 'group discrimination') and differentiation; implying that different groups or classes of users with different characteristics are charged different tolls. This is not the only form of discrimination. Under firstdegree price discrimination, or differentiation, each individual consumer can be charged a different price. Although this normally improves welfare, as it allows the producer to capture the whole consumer surplus in addition to its producer surplus, it is not usually allowed or even possible. Second-degree price discrimination, in which consumers are charged a price based on the quantity they consume, is much more common, but less so in passenger transportation markets.

Second, note that, in the transportation literature, a distinction is often made between 'full prices', i.e., private costs plus fares or tolls, and 'ticket prices', i.e., the fares or tolls only. Hence, there are also two potential types of differentiation and discrimination: in full prices and in ticket prices. If private costs depend on total usage levels, as they usually do in transportation markets, these two types are not the same. As the definitions in Eqs. 1-2 already indicates, this paper only considers ticket price discrimination and differentiation. Although others have also looked at discrimination in full prices (e.g. Czerny and Zhang, 2014), this type of discrimination is not usually observed in real-world markets, and would unnecessarily complicate the analysis.

Third, we only consider internal solutions: i.e., outcomes in which at least some users from each class travel. Corner solutions, in which one group does not travel, are certainly interesting, but difficult to analyze in a general setting, and the inclusion of the various corner solutions that exist would overcomplicate our exposition. We compare and contrast four cases: the social optimum, a monopoly, a monopoly where price differentiation is not allowed, and a monopoly where price discrimination is not allowed. We do not consider other forms of competition (e.g. oligopolies). We also do not comment on the impacts of marginal changes in price differences or discrimination on 
welfare, except where that is necessary to analyze a monopoly.

This paper shows that restricting a monopolist to charge uniform or non-discriminatory prices may increase or decrease social welfare, depending on the parameters of the model. Moreover, non-discriminatory pricing is not necessarily better than uniform pricing, even though the former is arguably the most 'fair' policy. In contrast to the simpler models developed in the existing literature, here, both policies have an impact on the total number of users even if all users have the same value of time. The results obtained from a single-link model can be generalized to a situation with serial links, where discrimination or differentiation is based on the origins and destinations of users. They cannot be generalized directly to a setting with parallel links, where differentiation is based on the routes that users take.

\section{Differentiation and discrimination on a single link}

\subsection{Social optimum}

In this model, there are two user classes, each with its own inverse demand function $\left(D_{1}\left(N_{1}\right)\right.$ and $D_{2}\left(N_{2}\right)$ ). Both inverse demand functions are continuously differentiable with first-order derivatives $D_{1}^{\prime}\left(N_{1}\right)<0$ and $D_{2} \prime\left(N_{2}\right)<0$. The two classes share the same link, and hence, impose negative congestion externalities on each other. Since the two classes may be composed of different types of vehicles, these externalities need not be symmetric; adding an additional user of one class may have a much larger effect on congestion than adding an additional user of the other. Apart from this difference in external costs, the two classes may also have different marginal private cost functions. They may, for instance, have a different value of time; although subject to the same level of congestion, this would lead the two classes to face different user costs. Reflecting these two potential differences, we define two user cost functions $c_{1}=\alpha c\left(\beta N_{1}+N_{2}\right)$, and $c_{2}=c\left(\beta N_{1}+N_{2}\right)$, where $\beta$ is a relative congestion coefficient, which captures the marginal external costs of class 1 users, relative to this in class 2 (e.g., a passenger car equivalent ${ }^{5}$ ). The $\alpha$ parameter measures how class 1 users value congestion, relative to class 2 (e.g., a relative value of time). ${ }^{6}$ We assume that $c(\cdot)$ is continuously differentiable with $c(\cdot)>0$. Social welfare is then the sum of the integrals of both demand functions, minus the total user costs:

$$
W=\int_{0}^{N_{1}} D_{1}(n) d n+\int_{0}^{N_{2}} D_{2}(n) d n-\left(\alpha N_{1}+N_{2}\right) c\left(\beta N_{1}+N_{2}\right)
$$

Depending on the functional form of the inverse demand and average user cost functions, it may be optimal to have only one group traveling. Assuming that both groups travel, a social planner sets fares $f_{1}$ and $f_{2}$ (charged to the first and second user class, respectively) and flows $N_{1}$ and $N_{2}$ to maximize $W$ s.t.

$$
\begin{gathered}
D_{1}\left(N_{1}\right)-\alpha c\left(\beta N_{1}+N_{2}\right)-f_{1}=0 \\
D_{2}\left(N_{2}\right)-c\left(\beta N_{1}+N_{2}\right)-f_{2}=0
\end{gathered}
$$

\footnotetext{
${ }^{5}$ Passenger car equivalents (PCEs), first introduced in the 1965 Highway Capacity Manual (HRB, 1965) are widely used in road transportation studies.

${ }^{6}$ E.g., both external and private costs of class 1 users are a linear function of those of class 2 . In general, this need not be the case, but without this assumption our models would become intractable.
} 
where the constraints ensure that marginal user costs plus fares equal marginal benefits, and hence, that the resulting equilibrium is consistent with the users' preferences.

Naturally, maximizing $W$ subject to these constraints gives $f_{1}=\left(\alpha N_{1}+N_{2}\right) \beta c^{\prime}$ and $f_{2}=$ $\left(\alpha N_{1}+N_{2}\right) c^{\prime}$, where, $c^{\prime}=\partial c / \partial n_{2}$ (i.e. if users in class 2 have passenger cars, the increase in cost resulting from the addition of one extra passenger-car equivalent); fares are equal to marginal social costs, such that all external costs are internalized by the users (see also Pigou, 1920; Knight, 1924). There is differentiation if $\beta \neq 1$ as, in that case, users have different marginal external costs. By definition, there is no discrimination: any differences in fares between the two groups are related to marginal cost differences.

\subsection{Unrestricted monopoly}

A monopolist maximizes $\pi=f_{1} N_{1}+f_{2} N_{2}$ subject to the same constraints as the social planner (Eqs. 4-5). The resulting fares are:

$$
\begin{gathered}
f_{1}=\left(\alpha N_{1}+N_{2}\right) \beta c^{\prime}-N_{1} D_{1}^{\prime} \\
f_{2}=\left(\alpha N_{1}+N_{2}\right) c^{\prime}-N_{2} D_{2}^{\prime}
\end{gathered}
$$

where $c^{\prime}=\partial c / \partial n_{2}$ and $D_{i}^{\prime}=\partial D_{i} / \partial n_{i}$. Again, this is not surprising. The monopolist charges a markup, in addition to the user's marginal external costs: both prices are higher than socially optimal, while both $N_{1}$ and $N_{2}$ are lower. Importantly, there is price differentiation if $\beta \neq 1$ and/or $D_{1}(n) \neq D_{2}(n)$. Price discrimination only occurs if $D_{1}(n) \neq D_{2}(n)$, regardless of the value of $\beta$.

Comparing welfare under unrestricted monopolistic pricing to the more restrictive policies without differentiation or discrimination that we will examine below is difficult without strong assumptions on the inverse demand- and cost functions. We can, however, analyze in which situations the composition of users is optimal, and how the total number of users changes with these policies.

Given a total number of users $N_{1}+N_{2}$, the composition of users (or share of users from each class) is optimal if $\triangle A \equiv \partial W / \partial N_{1}-\partial W / \partial N_{2}=0$. As long as this equality holds, it is not possible to increase welfare by decreasing the number of users from one class, while simultaneously increasing the number of users of the other class by the same amount. Using 3 ,

$$
\Delta A=\left(D_{1}-\alpha c\right)-\left(D_{2}-c\right)+\left(\alpha N_{1}+N_{2}\right)(1-\beta) c^{\prime}
$$

where the first two terms give the marginal change in private user benefits resulting from the marginal composition change, and the third term gives the marginal change in total costs. Substituting the first-order conditions of the unrestricted monopoly in this expression, this can be simplified to $\Delta A=N_{2} D_{2}^{\prime}-N_{1} D_{1}^{\prime}$; unless $N_{2} D_{2}^{\prime}=N_{1} D_{1}^{\prime}$ (which is unlikely to happen unless the two demand functions are equal), $\Delta A \neq 0$; the composition of users is not optimal in an unrestricted monopoly. Whether $\Delta A$ is positive or negative (and hence, whether $N_{1}$ or $N_{2}$ is higher then optimal) depends on the relative cost- and demand functions of the two classes. In theory then, a more restrictive pricing policy, which disallows price discrimination or differentiation, can improve welfare, even if it does not increase (or even reduces) the total number of travelers. This effect of a policy on the composition of users is sometimes called the 'allocation effect' (see, e.g., Czerny and Zhang, 2014)

Besides this allocation effect, a policy change may also affect the total number of travelers. This is sometimes called the 'output effect'. Although it is theoretically possible to analyze this 
output effect in a similar way as the allocation effect (i.e. by evaluating $\left(N_{1} /\left(N_{1}+N_{2}\right)\right) \partial W / \partial N_{1}+$ $\left(N_{2} /\left(N_{1}+N_{2}\right)\right) \partial W / \partial N_{2}$ : keeping the composition of users constant, but increasing the total), this is not useful here, as the total usage level will never be optimal in any of the monopolistic settings we examine. Using a metric like this, we could therefore only conclude that welfare can, in all cases, be increased by increasing the number of travelers, but not how it changes between two monopolistic settings. We can, however, examine how the restrictive policies change total usage levels, as we will see below.

This approach, combining information about the effect of restrictive policies on output with an analysis of the allocative efficiency of the resulting equilibria, is useful, because it does not need any assumptions about demand or congestion. It does, however, also have disadvantages. We can only say that a policy unambiguously increases welfare if it leads to an equilibrium where $\triangle A=0$, and does not decrease the total usage level. If $\Delta A \neq 0$, or the total number of users changes, we can only describe the output- and allocation effects, without knowing how they combine to affect welfare. Therefore, we will complement our analytical approach with a numerical example, in which we can more explicitly show how welfare changes when differentiation or discrimination is now allowed.

\subsection{Monopoly without price differentiation}

This situation is similar to the above, except that $f_{1}=f_{2}=f$. Hence, the monopolist now maximizes $\pi=f\left(N_{1}+N_{2}\right)$ s.t.

$$
\begin{gathered}
D_{1}\left(N_{1}\right)-\alpha c\left(\beta N_{1}+N_{2}\right)-f=0 \\
D_{2}\left(N_{2}\right)-c\left(\beta N_{1}+N_{2}\right)-f=0
\end{gathered}
$$

The optimal monopolistic fare can, in this case, be written as

$$
\begin{aligned}
f= & \left(N_{1}+N_{2}\right) c^{\prime} \frac{D_{1}^{\prime}+\alpha \beta D_{2}^{\prime}}{D_{1}^{\prime}+D_{2}^{\prime}-(\alpha-1)(\beta-1) c^{\prime}} \\
& -N_{1} D_{1}^{\prime} \frac{D_{2}^{\prime}}{D_{1}^{\prime}+D_{2}^{\prime}-(\alpha-1)(\beta-1) c^{\prime}} \\
& -N_{2} D_{2}^{\prime} \frac{D_{1}^{\prime}}{D_{1}^{\prime}+D_{2}^{\prime}-(\alpha-1)(\beta-1) c^{\prime}}
\end{aligned}
$$

This immediately shows why it is important to distinguish between price discrimination and differentiation: although there is now no differentiation, there is still discrimination if $\beta \neq 1$. More importantly, enforcement of uniform pricing usually leads to price discrimination: if $D_{1}(n)=D_{2}(n)$ (and hence, an unrestricted monopolist would not price discriminate, but only differentiate), the uniform price in Eq. 11 is discriminatory.

In general, the single fare $f$ consists of two parts. The first internalizes (some of) the marginal external costs. Since these differ across the two classes, the monopolist uses a weighted average, with the weights determined by the relative slopes of the inverse demand curves, corrected for the fact that the second group has a different congestion parameter $\beta$ and value of time $\alpha$ than the first. These parameters are taken into account because they co-determine the sensitivity of each class to sub-optimal prices. The second term is a weighted average of the two monopolistic markups, where, again, the weights are determined by the slopes of the inverse demand curves, and, if $\alpha \neq 1$ 
or $\beta \neq 1$, the slope of the cost function. Each class' weight is inversely proportional to its relative inverse demand slope; the more price-sensitive a class is (i.e., the flatter its inverse demand curve is), the closer the joint markup lies to what this class' own markup would be in an unrestricted monopoly.

Eq. 11 also illustrates that it is important to consider differences in external costs and internal cost functions together; only if both are present does the cost function influence the markup. In that case, the weights on $N_{1} D_{1}^{\prime}$ and $N_{2} D_{2}^{\prime}$ do not add up to one: the monopolistic markup is not just somewhere between the two markups in an unrestricted setting. This happens because, if users differ in two dimensions, it is not possible to charge the correct average external cost and average markup; each average needs to take into account that the other average is distortionary.

Under a uniform pricing policy, $\Delta A=\left(\alpha N_{1}+N_{2}\right)(1-\beta) c^{\prime}$. Hence, if $\beta=1$ (all users have the same marginal external cost; e.g., all drive the same type of vehicle), uniform pricing always leads to an optimal composition of users - a clear improvement over an unregulated monopoly. If $\beta<1$, $N_{2}$ is larger than optimal; if $\beta>1, N_{1}$ is larger than optimal. In the latter cases, uniform pricing could improve or deteriorate the composition of users, depending on the model parameters.

Determining the effect of uniform pricing on the total number of users is more complicated, as this total number is determined by the user equilibrium constraints, and does not have a closed form. Assuming, without loss of generality, that $f_{2} \geq f_{1}$ and following Czerny and Zhang (2014), we can define direct demand functions $N\left(f_{1}, f_{2}\right) \equiv N_{1}\left(f_{1}, f_{2}\right)+N_{2}\left(f_{1}, f_{2}\right)$ and a price difference $\phi \equiv f_{2}-f_{1} \geq 0$. The total derivative of $N$ with respect to the price difference can then be written as:

$$
\begin{aligned}
\frac{d N}{d \phi} & =\frac{\partial N}{\partial f_{1}} \frac{d f_{1}}{d \phi}+\frac{\partial N}{\partial f_{2}} \frac{d f_{2}}{d \phi} \\
& =\left(\frac{\partial N}{\partial f_{1}}+\frac{\partial N}{\partial f_{2}}\right) \frac{d f_{1}}{d \phi}+\frac{\partial N}{\partial f_{2}}
\end{aligned}
$$

Totally differentiating the user equilibrium conditions and using Cramer's Rule gives:

$$
\begin{aligned}
& \frac{\partial N_{1}}{\partial f_{1}}=\left(D_{2}^{\prime}-c^{\prime}\right) / \Omega<0 \\
& \frac{\partial N_{2}}{\partial f_{1}}=\beta c^{\prime} / \Omega>0 \\
& \frac{\partial N_{1}}{\partial f_{2}}=\alpha c^{\prime} / \Omega>0 \\
& \frac{\partial N_{2}}{\partial f_{2}}=\left(D_{1}^{\prime}-\alpha \beta c^{\prime}\right) / \Omega<0
\end{aligned}
$$

where $\Omega=\left|\begin{array}{cc}D_{1}^{\prime}-\alpha \beta c^{\prime} & -\alpha c^{\prime} \\ -\beta c^{\prime} & D_{2}^{\prime}-c^{\prime}\end{array}\right|=\left(D_{1}^{\prime}-\alpha \beta c^{\prime}\right)\left(D_{2}^{\prime}-c^{\prime}\right)-\alpha \beta c^{\prime 2}>0$. All partials and crosspartials have the expected signs. Hence,

$$
\begin{aligned}
& \frac{\partial N}{\partial f_{1}}=\left(D_{2}^{\prime}-(1-\beta) c^{\prime}\right) / \Omega \\
& \frac{\partial N}{\partial f_{2}}=\left(D_{1}^{\prime}-\alpha(\beta-1) c^{\prime}\right) / \Omega
\end{aligned}
$$


Interestingly, it is theoretically possible that one (but not both) of these partial derivatives is positive if $\beta$ is either very small, or very large. Because the link is congested, a fare increase for one user class will increase the number of users from the other. In some cases, this increase may be larger than the decrease in users from the first class.

Finally, totally differentiating the operator's profit function with respect to $f_{1}$ and $\phi$ gives

$$
\frac{d f_{1}}{d \phi}=-\frac{\partial^{2} \pi /\left(\partial f_{1} \partial \phi\right)}{\partial^{2} \pi /\left(\partial f_{1}\right)^{2}}
$$

where

$$
\frac{\partial^{2} \pi}{\left(\partial f_{1} \partial \phi\right)}=\frac{\partial N}{\partial f_{2}}+\frac{\partial N_{2}}{\partial f_{1}}+\frac{\partial N_{2}}{\partial f_{2}}+f_{1}\left(\frac{\partial^{2} N}{\partial f_{1} \partial f_{2}}+\frac{\partial^{2} N}{\left(\partial f_{2}\right)^{2}}\right)+\phi\left(\frac{\partial^{2} N_{2}}{\partial f_{1} \partial f_{2}}+\frac{\partial^{2} N_{2}}{\left(\partial f_{2}\right)^{2}}\right)
$$

and

$$
\begin{aligned}
\frac{\partial^{2} \pi}{\left(\partial f_{1}\right)^{2}}= & 2\left(\frac{\partial N}{\partial f_{1}}+\frac{\partial N}{\partial f_{2}}\right)+f_{1}\left(\frac{\partial^{2} N_{1}}{\left(\partial f_{1}\right)^{2}}+2 \frac{\partial^{2} N_{1}}{\partial f_{1} \partial f_{2}}+\frac{\partial^{2} N_{1}}{\left(\partial f_{2}\right)^{2}}\right) \\
& +\left(f_{1}+\phi\right)\left(\frac{\partial^{2} N_{2}}{\left(\partial f_{1}\right)^{2}}+2 \frac{\partial^{2} N_{2}}{\partial f_{1} \partial f_{2}}+\frac{\partial^{2} N_{2}}{\left(\partial f_{2}\right)^{2}}\right)
\end{aligned}
$$

In a linear case, then,

$$
\frac{d f_{1}}{d \phi}=-\frac{\left(2 D_{1}^{\prime}+\beta(1-\alpha) c^{\prime}+\alpha(1-\beta) c^{\prime}\right) / \Omega}{2\left(\frac{\partial N}{\partial f_{1}}+\frac{\partial N}{\partial f_{2}}\right)}
$$

and hence

$$
\frac{d N}{d \phi}=\frac{(\alpha-\beta) c^{\prime}}{2 \Omega}
$$

where $\Omega$, in this linear case, is a positive constant. Since a uniform pricing policy reduces $\phi$ from $f_{2}-f_{1}$ to zero, it increases output by the negative of the integral of Eq. 24 which, in a linear case, is $\left(f_{2}-f_{1}\right)(\beta-\alpha) c^{\prime} / 2 \Omega$.

Contrary to Czerny and Zhang (2014) (which, itself, generalizes Robinson, 1933), even if time valuations are the same for all users $(\alpha=1)$, this is not enough for the output effect to be zero if cost- and demand functions are linear; this only holds if $\alpha=\beta$ (such that each user's relative value of time is equal to its relative external cost). Since we have assumed that $f_{2} \geq f_{1}$, and the increase in the number of users for a specific fare difference is given by the integral of Eq. 24, the number of users is higher under uniform pricing only if $\alpha<\beta$; i.e., the user class that is charged the highest fare has a relatively low value of time, compared to its relative external cost.

For general demand- and cost functions, if $\beta>1$ and $d f_{1} / d \phi>0$ (i.e.; the lowest unrestricted fare is higher than the uniform fare), the total number of users always reduces if prices are differentiated (i.e. increases if a uniform pricing policy is enforced). If $d f_{1} / d \phi<-1$ (i.e. the highest unrestricted fare is lower than the uniform fare), output always increases with price differentiation. Usually, though, one would expect $-1<d f_{1} / d \phi<0$, in which case the sign of the output effect is then determined by the values of $\alpha, \beta$, and the Hessians of the two direct demand functions.

Taking the allocation and output effect together: it is, even in a linear world, only possible to determine that a uniform pricing policy is always welfare-enhancing if $\beta=1$ (such that the 
allocation effect is definitely positive) and $\alpha<1$ while $f_{2} \geq f_{1}$ (such that the output effect is non-negative). In all other cases, a uniform pricing policy may or may not be welfare-enhancing, depending on the model parameters. In the numerical example below, we will explore this further.

\subsection{Monopoly without price discrimination}

Again, the monopolist maximizes $\pi=f_{1} N_{1}+f_{2} N_{2}$, now s.t. Eqs. $4-5$ and

$$
f_{1}-\left(\alpha N_{1}+N_{2}\right) \beta c^{\prime}=f_{2}-\left(\alpha N_{1}+N_{2}\right) c^{\prime}
$$

Assuming, for tractability, that $c \prime \prime=0$,

$$
\begin{aligned}
f_{1}= & \left(\alpha N_{1}+N_{2}\right) \beta c^{\prime}-N_{1} D_{1}^{\prime} \frac{D_{2}^{\prime}+(\alpha-\beta) c^{\prime}}{D_{1}^{\prime}+D_{2}^{\prime}-2 \alpha(\beta-1) c^{\prime}} \\
& -N_{2}\left(D_{2}^{\prime}-(\beta-1) c^{\prime}\right) \frac{D_{1}^{\prime}+(\alpha+\beta-2 \alpha \beta) c^{\prime}}{D_{1}^{\prime}+D_{2}^{\prime}-2 \alpha(\beta-1) c^{\prime}} \\
f_{2}= & \left(\alpha N_{1}+N_{2}\right) c^{\prime}-N_{1} D_{1}^{\prime} \frac{D_{2}^{\prime}+(\alpha-\beta) c^{\prime}}{D_{1}^{\prime}+D_{2}^{\prime}-2 \alpha(\beta-1) c^{\prime}} \\
& -N_{2}\left(D_{2}^{\prime}-(\beta-1) c^{\prime}\right) \frac{D_{1}^{\prime}+(\alpha+\beta-2 \alpha \beta) c^{\prime}}{D_{1}^{\prime}+D_{2}^{\prime}-2 \alpha(\beta-1) c^{\prime}}
\end{aligned}
$$

In the non-differentiated setting above, the monopolist charged all users an average marginal cost, plus an average markup. Here, it charges each user class its actual marginal costs. This, in turn, also affects the markup. Even though this markup is, by definition, still independent of class, the operator exploits the fact that it can at least charge every class its own marginal costs, and consequently sets a higher markup than in Eq. 11. The weights on $N_{1} D_{1}^{\prime}$ and $N_{2} D_{2}^{\prime}$ are now considerably more complex, but are still inversely related to each class' own inverse demand slope. If $\beta \geq 1$, such that the first user class pays the highest fare, the average markup moves closer to that of the first class in an unrestricted monopoly when its relative value of time $\alpha$ decreases.

The non-discrimination constraint ensures that $\Delta A=0$; by definition, the marginal change in user benefits (i.e., the difference between $f_{1}$ and $f_{2}$ ) resulting from a marginal change in user composition is equal to the marginal change in social costs. Hence, under this policy, the composition

of users is always optimal and the allocation effect is always positive. Determining the effect of non-discriminatory pricing on output is more difficult, as Eq. 24 can not be applied here. In this case, we cannot simply define $\phi$ as the difference in fares; it then depends on $N_{1}$ and $N_{2}$, and cannot be treated as an exogenous variable. We must now define $\phi \equiv f_{2}-f_{1}-\triangle m e c$. where $\triangle m e c=\left(N_{1}+\alpha N_{2}\right)(1-\beta) c$. If discrimination is not allowed, $\phi=0$. Using the same technique as before,

$$
\begin{aligned}
\frac{d N}{d \phi} & =\frac{\partial N}{\partial f_{1}} \frac{d f_{1}}{d \phi}+\frac{\partial N}{\partial f_{2}} \frac{d f_{2}}{d \phi} \\
& =\left(\frac{\partial N}{\partial f_{1}}+\frac{\partial N}{\partial f_{2}}\right) \frac{d f_{1}}{d \phi}+\frac{\partial N}{\partial f_{2}}+\frac{\partial N}{\partial f_{2}} \frac{d \triangle m e c c}{d \phi}
\end{aligned}
$$

Note the third term, which was not present in the no-differentiation analysis; this now appears because $\phi$ is now not simply the difference in fares, but the difference in fares minus the difference in marginal external costs. This term can be written as 


$$
\frac{d \triangle m e c c}{d \phi}=\left(\frac{d N_{1}}{d \phi}+\alpha \frac{d N_{2}}{d \phi}\right)(1-\beta) c^{\prime}+\left(N_{1}+\alpha N_{2}\right)(1-\beta) \frac{d c^{\prime}}{d \phi}
$$

which only disappears if $\beta=1$, and has no clearly cut sign. The addition of this term means that, even if cost- and demand functions are linear, and $\alpha=\beta$, the total usage level may be different under a non-discriminatory policy than under an unrestricted monopoly. As we will show in the numerical example below, it may be higher or lower, depending on the model parameters. Hence, even though the absence or presence of price differentiation does not change the total number of users when $\alpha=\beta$, the absence or presence of price discrimination does have an effect.

In conclusion; a non-discriminatory policy always has a positive allocation effect: it always leads to an optimal composition of users. It may also increase the number of users, and hence, would be socially beneficial. In a linear world, this is guaranteed to happen if $\beta=1$ (all users have the same marginal external cost) and the class that is charged the lowest fare also has the lowest value of time. However, like uniform pricing, non-discriminatory pricing may also decrease the number of users, and have a potentially negative impact on welfare. Finally, there is no guarantee that non-discriminatory pricing is always better policy than uniform pricing, as we shall see in more detail below.

\subsection{Numerical example}

Fig. 4 illustrate these issues, for a very simple linear case. In all panels, $c=10+0.1\left(\beta N_{1}+N_{2}\right)$. In the panels on the left, (a) and (c), $D_{1}=100-N_{1}$ and $D_{2}=65-N_{2}$. In the other two panels, the inverse demand functions are reversed, such that $D_{1}=65-N_{1}$ and $D_{2}=100-N_{2}$. Finally, in the two top panels, (a) and (b), $\alpha=1$, whereas in the bottom panels, $\alpha=3$. The vertical axis in both panels denotes the relative efficiency $\omega$ of the non-differentiated and nondiscriminatory monopolistic prices; i.e. the difference in welfare between these settings and an unrestricted monopoly, relative to the difference in welfare between the first-best social optimum and an unrestricted monopoly (Verhoef et al., 1995). If $\omega<0$, an unrestricted monopoly is better than the restrictive policy; a higher $\omega$ means that a policy is closer to the social optimum.

Fig. 4 shows that, even with simple linear demand- and cost functions, the effects of uniform or non-discriminatory pricing policies are ambiguous. Either policy can potentially increase or decrease welfare, relative to an unrestrictive monopoly, depending on the model parameters.

Looking at the results of uniform pricing: as we have shown above, the output effect disappears if $\alpha=\beta$ (at $\beta=1$ in the top panels, and at $\beta=3$ in the bottom panels). What is left over can only be the allocation effect. Clearly, this can be positive or negative. Hence, uniform pricing can improve welfare, but it can also decrease it. In this linear example, the latter is mostly likely to happen if the class with the highest reservation price also has a much higher external cost than the other class.

For non-discriminatory pricing, the output effect disappears only if $\alpha=\beta=1$; in that case, only the positive allocation effect remains. In other cases, the output effect may be negative, and large enough to offset the allocation effect; it may also be positive, and work in the same direction as the allocation effect. Hence, enforcing non-discrimination sometimes, but certainly not always, improves welfare.

Uniform pricing is sometimes better than non-discriminatory pricing. In this linear example, this happens if the class with the highest reservation price has a lower external cost than the other 
(a) $D_{1}=100-N_{1}, D_{2}=65-N_{2}, \alpha=1$

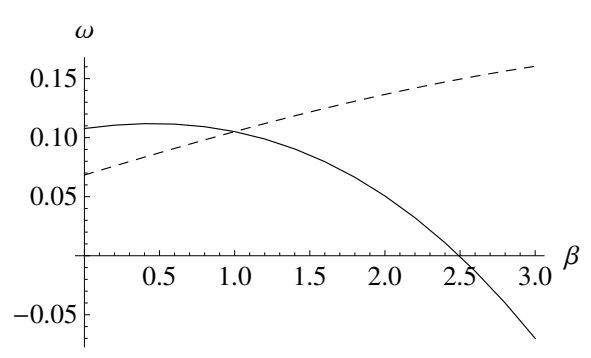

(c) $D_{1}=100-N_{1}, D_{2}=65-N_{2}, \alpha=3$

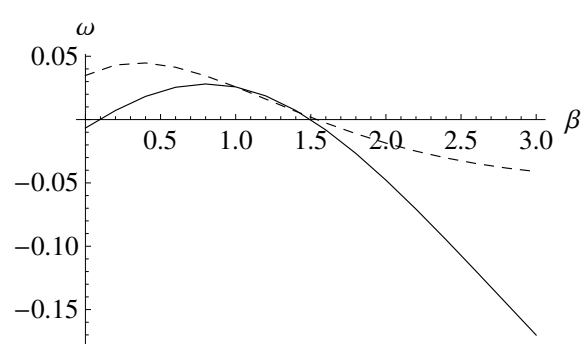

(b) $D_{1}=65-N_{1}, D_{2}=100-N_{2}, \alpha=1$

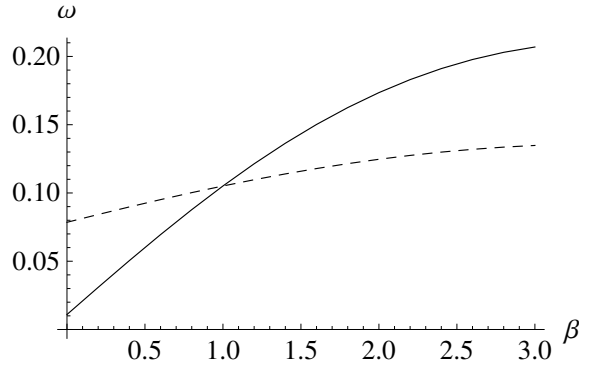

(d) $D_{1}=65-N_{1}, D_{2}=100-N_{2}, \alpha=3$

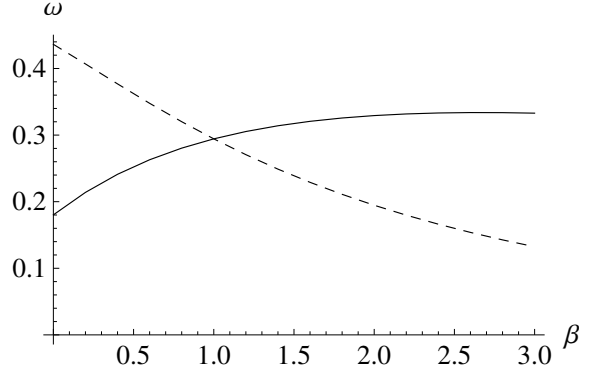

Non-differentiation
- - - - - - - - Non-discrimination

Figure 4: Model 1 - Numerical example 
class (e.g. a morning peak on a highway if the inverse demand function for cars always lies above the inverse demand function for trucks, as may be expected) while both classes have the same value of time. In that case, uniform pricing induces a monopolist to increase output, relative to an unrestricted setting, by so much that, even though a non-discriminatory policy would lead to a better composition of users, uniform pricing is still better. If the classes also have different values of time, this effect is parameter-dependent. This does show, however, that a pricing strategy that is considered the most 'fair' may not be the best in terms of social welfare. Naturally, if $\beta=1$, uniform pricing and non-discrimination are the same. As panel (c) shows, there may also be other $\beta$ 's for which this holds, even in this linear case.

\section{$3 \quad$ Network effects - serial links}

\subsection{Social optimum}

In the previous model, we considered a situation in which multiple user classes travel between the same two nodes, using one link. Here, we consider a setting with three nodes, connected by two serial links. As before, there are different user classes; however, these differ not only in their values of time and congestion parameters, but also in origin and destination. Users from the first class travel between nodes 1 and 2, using only the first link. The second class uses the second link to travel between nodes 2 and 3, and, finally, the third class travels from 1 to 3 , using both links.

We simplify this model by assuming that the two links have the same congestion functions $c$. We also assume that the inverse demand functions for short-distance travel (from 1 to 2 and from 2 to 3 ) are the same, such that the model becomes symmetric: fares and usage levels will be the same on both links. The short-distance inverse demand functions are then given by $D_{s}\left(N_{s}\right)$, where $N_{s}$ is the number of short-distance travelers on each of the two links, while the long-distance inverse demand function is given by $D_{l}\left(N_{l}\right)$. We do allow for the possibility of long-distance travelers having a different relative value of time $\alpha$, and a different congestion coefficient $\beta$, than shortdistance travelers. Hence, all short-distance travelers face $\operatorname{costs} c\left(\beta N_{l}+N_{s}\right)$, while long-distance travelers incur costs $2 \alpha c\left(\beta N_{l}+N_{s}\right)$.

The assumed symmetry of this model allows us to obtain more compact expressions for the monopolistic fares, and for the welfare effects. However, as we will discuss below, and show in the appendix, the qualitative results do not depend on this assumption. A model with two different cost functions, one for each of the links, or different inverse demand functions for each of the three user classes, will not produce fundamentally different insights, especially when it comes to the effect of price differentiation on the total number of users.

Given a symmetric solution, social welfare is given by

$$
W=2 \int_{0}^{N_{s}} D_{s}(n) d n+\int_{0}^{N_{l}} D_{l}(n) d n-2\left(\alpha N_{l}+N_{s}\right) c\left(\beta N_{l}+N_{s}\right)
$$

A social planner sets the fares for long-distance and short distance-travel, $f_{s}$ and $f_{1}$, and the corresponding usage levels, maximizing $W$. Similar to the previous model, there are two user equilibrium constraints:

$$
\begin{array}{r}
D_{s}\left(N_{s}\right)-c\left(\beta N_{l}+N_{s}\right)-f_{s}=0 \\
D_{l}\left(N_{l}\right)-2 \alpha c\left(\beta N_{l}+N_{s}\right)-f_{l}=0
\end{array}
$$


Naturally, maximizing $W$ subject to these constraints results in simple marginal-cost pricing rules: $f_{s}=\left(\alpha N_{l}+N_{s}\right) c^{\prime}$ and $f_{l}=2 \beta\left(\alpha N_{l}+N_{s}\right) c^{\prime}$. Even if all users have the same congestion coefficient $\beta$, long-distance travelers still pay a higher fare than short-distance travelers, simply because they cause congestion on two links, instead of just one.

\subsection{Unrestricted monopoly}

If it can set separate fares for short- and long-distance travelers, the monopolist maximizes $\pi=$ $2 f_{s} N_{s}+f_{l} N_{l}$, s.t. Eqs. 32-33. With no restrictions on these fares, the monopolist can differentiate and discriminate between users from different OD-pairs. If $f_{l} \neq 2 f_{s}$, long-distance travelers pay a different fare for use of at least one of the two links than short-distance travelers. This unrestricted setting is sometimes called 'OD-based pricing' (e.g., Ohazulike et al. (2013)), and leads to fares $f_{s}=\left(\alpha N_{l}+N_{s}\right) c^{\prime}-N_{s} D_{s}^{\prime}$ and $f_{l}=2 \beta\left(\alpha N_{l}+N_{s}\right) c^{\prime}-N_{l} D_{l}^{\prime}$. Again, these fares internalize external costs, and include a monopolistic demand-related markup.

Note that, contrary to the one-link model above, fares are still differentiated if all inverse demand functions are equal and all users have the same congestion coefficient. Instead, only if long-distance users cause exactly half as much as congestion as short-distance travelers can both fares be the same. As before, they are discriminatory if the two demand functions are different.

To measure whether the composition of users on each link is optimal, given a total number of users, we can again define a $\triangle A$, as the change in welfare when the number of users from one group is increased, while the total number of users is kept constant. There are now two of these total usage levels, one on each link; both are kept constant if

$$
\triangle A \equiv \frac{\partial W}{\partial N_{l}}-\frac{\partial W}{\partial N_{s}}
$$

Using the monopolistic fares and first-order conditions, $\triangle A=2 N_{s} D_{s}^{\prime}-N_{l} D_{l}^{\prime}$. Hence, in general, $\triangle A \neq 0$; a more restrictive policy can increase social welfare, even if does not change the usage levels on both links, or even decreases them. Of course, as usual in a monopoly, usage levels are also lower than optimal; increasing the total number of users on each link will also increase welfare.

\subsection{Monopoly without price differentiation}

If the monopolist cannot discriminate between users traveling between different OD-pairs, but has to charge each user traveling on the same link the same price $f_{s}$ (and hence, $f_{l}=2 f_{s}$. This situation is sometimes called 'link-based pricing'; see van der Weijde et al. (2013) for an examples), it maximizes $\pi=2 f_{s}\left(N_{s}+N_{l}\right)$ s.t.

$$
\begin{aligned}
D_{s}\left(N_{s}\right)-c\left(\beta N_{l}+N_{s}\right)-f_{s} & =0 \\
D_{l}\left(N_{l}\right)-2 \alpha c\left(\beta N_{l}+N_{s}\right)-2 f_{s} & =0
\end{aligned}
$$

The profit-maximizing fare is given by 


$$
\begin{aligned}
f= & \left(N_{l}+N_{s}\right) c^{\prime} \frac{D_{l}^{\prime}+2 \alpha \beta D_{s}^{\prime}}{D_{l}^{\prime}+2 D_{s}^{\prime}-2 c^{\prime}(\alpha-1)(\beta-1)} \\
& -N_{l} D_{l}^{\prime} \frac{D_{s}^{\prime}}{D_{l}^{\prime}+2 D_{s}^{\prime}-2 c^{\prime}(\alpha-1)(\beta-1)} \\
& -N_{s} D_{s}^{\prime} \frac{D_{l}^{\prime}}{D_{l}^{\prime}+2 D_{s}^{\prime}-2 c^{\prime}(\alpha-1)(\beta-1)}
\end{aligned}
$$

which is almost the same expression as for our first model; the only difference being the double weight on $D_{l}$ ' in the denominator of all three elements (as one long-distance traveler could replace two short-distance travelers), and in the numerator of the first. Naturally, this causes fares to be discriminatory if $\beta \neq 1 / 2$; if $\beta=1 / 2$, a long-distance traveler imposes half the congestion externality of short-distance travelers on twice as many users, such that all users have the same marginal external costs.

Under uniform pricing, $\triangle A=2\left(\alpha N_{l}+N_{s}\right)(1-\beta) c$. This means that, if $\beta<1$, there too many short-distance travelers on both links, while if $\beta>1$, there are too many long-distance travelers. Uniform pricing may have a positive or negative allocation effect, depending on the model parameters. If $\beta=1$, the allocation of users is optimal; in that case, uniform pricing always has a positive allocation effect.

Determining what happens to the total number of users on each link is somewhat more complicated than for the one-link model above; However, it is still possible to define a fare difference $\phi \equiv 2 f_{2}-f_{1}$, and analyze the impact of an increase in $\phi$ on the usage levels $N_{s}+N_{l}$. The derivations can be found in the appendix but, perhaps surprisingly, the results are exactly the same as those obtained for the one-link model above: in a a linear case

$$
\frac{d\left(N_{s}+N_{l}\right)}{d \phi}=\frac{(\alpha-\beta) c^{\prime}}{2 \Omega}
$$

where, here,

$$
\Omega=\left|\begin{array}{cc}
D_{s}^{\prime}-c^{\prime} & -\beta c^{\prime} \\
-2 \alpha c^{\prime} & D_{l}^{\prime}-2 \alpha \beta c^{\prime}
\end{array}\right|>0
$$

and hence, the total change in usage levels as a result of uniform pricing is given by $\left(2 f_{2}-f_{1}\right)(\alpha-\beta) c^{\prime} / 2 \Omega$. In a nonlinear case, the expressions are slightly different, as the cross-derivatives of the usage levels with respect to both fares are assigned different weights, but they are qualitatively the same. In the same way, it is possible to show that, even if the two short-distance inverse demand functions are different, and if the two links have different cost functions, $\phi$ still has no impact on the usage level of either of the two links.

This has several implications for the welfare effects of uniform pricing. Firstly, and most importantly, the network context has no qualitative impact here: if all users' values of time are equal to their congestion coefficients, uniform pricing does not change the usage levels of the individual links. In other words, OD-based price discrimination in a network is exactly the same as price differentiation between user classes traveling on the same link. This may sound surprising, but it is important to remember that it is not the same as saying that the total number of users in the network remains constant. The latter is obviously not the case if there is also an allocation effect.

This also means that, as before, output can be higher under uniform pricing. Here, this happens if $\left(2 f_{2}-f_{1}\right)(\alpha-\beta)<0$, or, substituting in the unrestricted monopolistic fares, if $\alpha-\beta$ and 
$2(1-\beta)\left(\alpha N_{l}+N_{s}\right) c^{\prime}-2 N_{s} D_{s}^{\prime}+N_{l} D_{l}^{\prime}$ have opposite signs. There is nothing in the model that prevents this from happening; it is solely determined by the model parameters.

\subsection{Monopoly without price discrimination}

If the monopolistic operator is not allowed to discriminate, it maximizes the same profit as in an unrestricted setting, subject to the same user equilibrium constraint, as well as a non-discrimination condition:

$$
2 f_{s}-f_{l}+2(\beta-1)\left(\alpha N_{l}+N_{s}\right) c^{\prime}=0
$$

If this equality does not hold, price discrimination occurs on at least one of the links.

The resulting fares are given by

$$
\begin{aligned}
f_{s}= & \left(\alpha N_{l}+N_{s}\right) c^{\prime}-N_{s} D_{s}^{\prime} \frac{D_{l}^{\prime}-(3 \alpha-2 \beta-\alpha \beta) c^{\prime}}{D_{l}^{\prime}+2 D_{s}^{\prime}+c l(4+\alpha)(\beta-1)} \\
& -N_{l}\left(D_{l}^{\prime}+3 \alpha(\beta-1) c^{\prime}\right) \frac{D_{s}^{\prime}+(\alpha+\beta-2) c^{\prime}}{D_{l}^{\prime}+2 D_{s}^{\prime}+c^{\prime}(4+\alpha)(\beta-1)} \\
f_{l}= & 2\left(\alpha N_{l}+N_{s}\right) \beta c^{\prime}-2 N_{s} D_{s}^{\prime} \frac{D_{l}^{\prime}-(3 \alpha-2 \beta-\alpha \beta) c^{\prime}}{D_{l}^{\prime}+2 D_{s}^{\prime}+c^{\prime}(4+\alpha)(\beta-1)} \\
& -2 N_{l}\left(D_{l}^{\prime}+3 \alpha(\beta-1) c^{\prime}\right) \frac{D_{s}^{\prime}+(\alpha+\beta-2) c^{\prime}}{D_{1}^{\prime}+2 D_{s}^{\prime}+c^{\prime}(4+\alpha)(\beta-1)}
\end{aligned}
$$

assuming that $c^{\prime \prime}=0$, for tractability. Although the expression for the uniform fare in this model was very similar to its corresponding expression in the first model above, the difference is larger here; in the weights multiplying the two markups, the cost function is multiplied by a much more complex function of $\alpha$ and $\beta$. The structure of the expressions is still the same: they consist of each class' marginal costs, plus a weighted average monopolistic markup. If $\beta \leq 1$, such that long-distance travelers have a lower relative congestion coefficient, the average markup is closer to the unrestricted long-distance markup if $\alpha$ is lower; this is also likely, though not guaranteed, to happen if $\beta>1$. As before, these fare non-discriminatory fares always lead to differentiation on at least one of the two links if $\beta \neq 1$.

As in the one-link model, the non-discrimination condition ensures that $\triangle A=0$. The output effect is ambiguous in sign, and not equal to zero even in a linear world where $\alpha=\beta$, as the fare difference $\phi$ is endogenous.

\section{Network effects - parallel links}

\subsection{Social optimum}

In this model, there is only one inverse demand function, $D\left(N_{1}+N_{2}\right)$. However, users can now take two routes, where each route has its own average user cost; $c_{1}\left(N_{1}\right)$ and $c_{2}\left(N_{2}\right)$, respectively. Note that this is similar to some of the two-period models available in the literature (see e.g., Liu and McDonald, 1999); here, the two alternatives are perfect substitutes. Social welfare is then given by 


$$
W=\int_{0}^{N_{1}+N_{2}} D(n) d n-N_{1} c_{1}\left(N_{1}\right)-N_{2} c_{2}\left(N_{2}\right)
$$

A social planner chooses $f_{1}$ (for route 1 ) and $f_{2}$ (for route 2 ) to maximize $W$, subject to two user equilibrium constraints that ensure that sum of the average user costs and the fare is the same for both routes, and equal to the marginal user benefits:

$$
\begin{aligned}
& D\left(N_{1}+N_{2}\right)-c_{1}\left(N_{1}\right)-f_{1}=0 \\
& D\left(N_{1}+N_{2}\right)-c_{2}\left(N_{1}\right)-f_{2}=0
\end{aligned}
$$

and hence, naturally, $f_{1}=N_{1} c_{1}^{\prime}$ and $f_{2}=N_{2} c_{2}^{\prime}$

\subsection{Unrestricted monopoly}

A monopolist maximizes $f_{1} N_{1}+f_{2} N_{2}$ s.t. the same two constraints as the social planner. Hence,

$$
\begin{aligned}
& f_{1}=N_{1} c_{1}^{\prime}-\left(N_{1}+N_{2}\right) D^{\prime} \\
& f_{2}=N_{2} c_{2}^{\prime}-\left(N_{1}+N_{2}\right) D^{\prime}
\end{aligned}
$$

These fares are always non-discriminatory; $f_{1}-N_{1} c_{1}^{\prime}=f_{2}-N_{2} c_{2}^{\prime}$; a non-discriminatory policy would not change anything. Moreover, the distribution of users over the two links is always optimal, as $\Delta A \equiv \partial W / \partial N_{1}-\partial W / \partial N_{2}=0$. This means that a more restrictive policy always has a negative allocation effect; uniform pricing can only increase welfare if it increases the total number of users.

\subsection{Monopolistic pricing without differentiation}

In this setting, $f_{1}=f_{2}=f$. Hence, the operator maximizes $f\left(N_{1}+N_{2}\right)$ s.t. $D\left(N_{1}+N_{2}\right)-c_{1}\left(N_{1}\right)-$ $f=0$ and $D\left(N_{1}+N_{2}\right)-c_{2}\left(N_{1}\right)-f=0$

This gives

$$
f=N_{1} c_{1}^{\prime} \frac{c_{2}^{\prime}}{c_{1}^{\prime}+c_{2}^{\prime}}+N_{2} c_{2}^{\prime} \frac{c_{1}^{\prime}}{c_{1}^{\prime}+c_{2}^{\prime}}-\left(N_{1}+N_{2}\right) D^{\prime}
$$

In contrast to the two models above, the operator still charges the same demand-related markup on both routes; this is natural, as there is only one demand function. The cost functions are different, so, instead of charging users of each route their marginal cost, the operator charges a weighted average marginal cost, with weights determined by the relative marginal costs. This time, the weight do sum to one: users only differ in one dimension, so only the part of the fare that is related to marginal costs needs to be averaged across groups. There are no further distortions, and hence, the monopolistic markup does not need any correction. If $N_{1} c_{1}^{\prime} \neq N_{2} c_{2}^{\prime}$ (which will happen if $\left.c_{1}(\cdot) \neq c_{2}(\cdot)\right)$, these fares are discriminatory.

Again, we consider the effects of a non-differentiated pricing policy by separately looking at the allocation and output effects. In this model, : $\Delta A=-N_{1} c_{1}^{\prime}+N_{2} c_{2}^{\prime}$, so, in general $\Delta A \neq 0$ : the distribution of users over the two links is not optimal. As we have already established, an 
unrestricted monopoly does lead to an optimal composition, so uniform pricing always has a negative allocation effect.

As before, we can determine the effect of price differentiation on the total number of users by defining a fare difference $\phi \equiv f_{2}-f_{1}$. Totally differentiating the direct demand function $N\left(f_{1}, f_{1}+\phi\right) \equiv N_{1}\left(f_{1}, f_{1}+\phi\right)+N_{2}\left(f_{1}, f_{1}+\phi\right)$ gives

$$
\frac{d N}{d \phi}=\frac{\partial N}{\partial f_{1}} \frac{d f_{1}}{d \phi}+\frac{\partial N}{\partial f_{2}} \frac{d f_{2}}{d \phi}=\left(\frac{\partial N}{\partial f_{1}}+\frac{\partial N}{\partial f_{2}}\right) \frac{d f_{1}}{d \phi}+\frac{\partial N}{\partial f_{2}}
$$

Totally differentiating the user equilibrium conditions and using Cramer's rule gives expression for $\partial N / \partial f_{1}$ and $\partial N / \partial f_{2}$; substituting these in the expression above gives

$$
\frac{d N}{d \phi}=-\frac{1}{\Omega}\left(\left(c_{1}^{\prime}+c_{2}^{\prime}\right) \frac{\partial f_{1}}{\partial \phi}+c_{1}^{\prime}\right)
$$

where

$$
\Omega \equiv\left|\begin{array}{cc}
D^{\prime}-c_{1}^{\prime} & D^{\prime} \\
D^{\prime} & D^{\prime}-c_{2}^{\prime}
\end{array}\right|>0
$$

This means that, if $\frac{\partial f_{1}}{\partial \phi}>0$, the total number of users decreases in the amount of differentiation (and hence, that a uniform pricing policy increases output). If $\frac{\partial f_{1}}{\partial \phi}<-1$, a uniform pricing policy decreases output. More generally, as before

$$
\frac{\partial f_{1}}{\partial \phi}=-\frac{\partial^{2} \pi /\left(\partial \phi \partial f_{1}\right)}{\partial^{2} \pi /\left(\partial f_{1}\right)^{2}}
$$

where the nominator can be written as

$$
\frac{\partial^{2} \pi}{\left(\partial \phi \partial f_{1}\right)}=-\frac{2 c_{1}^{\prime}}{\Omega}+f_{1}\left(\frac{(\partial N)^{2}}{\partial f_{1} \partial f_{2}}+\frac{\partial^{2} N}{\left(\partial f_{2}\right)^{2}}\right)+\phi\left(\frac{\left(\partial N_{1}\right)^{2}}{\partial f_{1} \partial f_{2}}+\frac{\partial^{2} N_{1}}{\partial^{2} f_{2}}\right)
$$

and the denominator is positive. In a linear case, then,

$$
\frac{\partial f_{1}}{\partial \phi}=-\frac{-\frac{1}{\Omega} 2 c_{1}^{\prime}}{2\left(\frac{\partial N}{\partial f_{1}}+\frac{\partial N}{\partial f_{2}}\right)}=-\frac{c_{1}^{\prime}}{c_{1}^{\prime}+c_{2}^{\prime}}
$$

and hence, $d N / d \phi=0$; there is no output effect. As the allocation effect is negative, uniform pricing always decreases welfare. If the demand function is non-linear, the second an third terms in Eq. 52 are nonzero, and the output effect may be positive or negative, depending on the Hessian of the direct demand functions.

\subsection{Monopolistic pricing without discrimination}

As already mentioned before, non-discrimination constraints would not be binding here; the unrestricted monopoly is already non-discriminatory. Discrimination only occurs if different users are charged a different monopolistic markup, which, in turn, can only happen if they have different demand structures. 


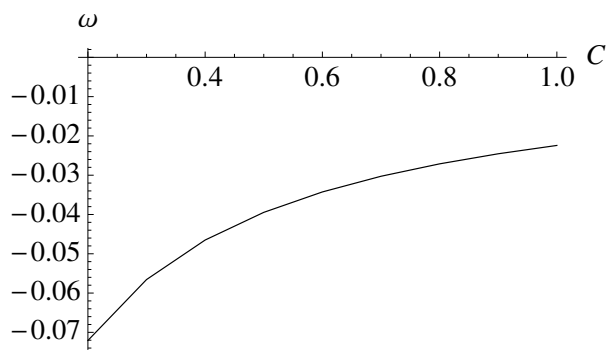

Figure 5: Model 3 - Numerical example

\subsection{Numerical example}

Fig. 5 shows the results of a numerical simulation in which $c_{1}=10+.1 N_{1}, c_{2}=1.5+C \cdot N_{2}$ and $D=100-\left(N_{1}+N_{2}\right)$. As before, the vertical axis shows the relative efficiency of, in this case, the uniform pricing policy, compared to an unrestricted monopoly. Naturally, $\omega$ is always negative: in this linear example, $N_{1}+N_{2}$ is the same, regardless of whether prices are differentiated or uniform, while the socially optimal division of travelers over the two links is optimal in the unrestricted monopoly. As $C$ increases, the number of users on the second link becomes smaller, and the uniform fare $f$ is set closer to what $f_{1}$ would be in an unrestricted monopoly. This reduces the allocative inefficiency of the uniform pricing policy; eventually, if $C$ becomes large enough, no travelers would take the second link, and price differentiation would not affect welfare at all.

\section{Conclusions}

In this paper, we have analyzed price discrimination and price differentiation in transport networks. As we have shown, it is important to make the distinction between differentiation and discrimination in this context, especially if users have different values of time, or marginal costs differ for other reasons.

Our models show that enforcing uniform or non-discriminatory pricing policies can, in some circumstances, improve social welfare, but decrease welfare in others. Importantly, although a non-discriminatory policy may be considered the most 'fair' by users, it is not always better than uniform pricing, even if users have different marginal costs.

Generalizing the existing literature, we have examined a situation in which users not only have different marginal private costs (e.g., as a result of different values of time), but also different marginal external costs (e.g., because they are driving different passenger-car equivalents). This does matter: in a linear world, for instance, price differentiation still affects total usage levels even if all users have the same value of time. Only if each user's relative value of time is equal to its relative marginal external cost does this effect disappear. Non-discrimination, on the other hand, always improves the composition of users, but may increase or decrease the total number even in a linear model where each user's relative value of time is equal to its relative marginal cost, as marginal external costs depend on usage levels.

In addition to this analysis of price discrimination and discrimination on a single link, we have also considered situations in which there are parallel or serial links, and transport operators can differentiate and/or discriminate based on the route users take, or on their origin. In a network 
with serial links, a monopolistic operator may be able to discriminate based on users' origins and destinations. As we have shown, this type of discrimination is not qualitatively different than discrimination based on values of time or marginal external costs. Although the monopolist's fare setting rules are different, all conclusions obtained in a one-link model generalize to a network with serial links.

Route-based discrimination, as may occur in networks with parallel links, is different than OD-based discrimination. If demand is linear, enforcing uniform pricing over multiple routes can never increase welfare. More generally, uniform pricing can only increase welfare if it substantially increases the usage level, because, if the only difference between users if the route they take, an unrestricted monopolist will set fares such that the division of users over the routes is optimal. An unregulated monopoly is already non-discriminatory if chosen route is the only difference between users.

Naturally, all three models we have examined are highly stylized. Any real-world network will simultaneously have parallel and serial links, and many different user classes traveling along them, between different OD-pairs. However, our stylized models do highlight the need for careful, situation-based analysis to evaluate the potential benefits of restrictive pricing policies. Neither uniform nor non-discriminatory pricing policies are universally welfare-enhancing (as first-degree price discrimination usually is) or universally decrease welfare (as a single-link linear model where all users have the same value of time would suggest). They also illustrate the need to distinguish between differentiation and discrimination. Although non-discrimination may be perceived as more 'fair', it is not always the best.

Our results also have implications for network modeling. Because of its computational advantages, link-based pricing, where operators do not differentiate based on OD-pairs, but charge all users the same for use of a link, is often assumed. If real-world transport operators are able to charge OD-based fares, these link-based models may understate or overstate the benefits of other types of regulation.

\section{References}

Adachi, T., 2005. Third-degree price discrimination, consumption externalities and social welfare. Economica 72, 171-178.

Adams, W. J., Yellen, J. L., 1976. Commodity bundling and the burden of monopoly. The Quarterly Journal of Economics 90 (3), 475-498.

Al-Kaisy, A. F., Hall, F. L., Reisman, E. S., 2002. Developing passenger car equivalents for heavy vehicles on freeways during queue discharge flow. Transportation Research Part A: Policy and Practice 36 (8), 725-742.

Chen, Y., Schwartz, M., 2013. Differential pricing when costs differ: a welfare analysis. Georgetown University, Department of Economics Working Paper 1301.

Czerny, A. I., Zhang, A., March 2014. Third-degree price discrimination in the presence of congestion externality.

HRB, 1965. Highway capacity manual - 1965. HRB Special Report 87. 
Knight, F., 1924. Some fallacies in the interpretation of social costs. Quarterly Journal of Economics $38,582-606$.

Liu, L. N., McDonald, J. F., 1999. Economic efficiency of second-best congestion pricing schemes in urban highway systems. Transportation Research Part B: Methodological 33 (3), 157-188.

Nocke, V., Peitz, M., Rosar, F., 2011. Advance-purchase discounts as a price discrimination device. Journal of Economic Theory 146, 141-162.

Ohazulike, A. E., Still, G., Kern, W., van Berkum, E. C., 2013. An origin-destination based road pricing model for static and multi-period traffic assignment problems. Transportation Research Part E: Logistics and Transportation Review 58, 1-27.

Pigou, A. C., 1920. The economics of welfare. Macmillan, London.

Robinson, J., 1933. The Economics of Imperfect Competition. Macmillan, London.

Stigler, G. J., 1986. The theory of price, 4th Edition. Macmillan, New York.

Stole, L. A., 2007. Price discrimination and competition. In: Armstrong, M., Porter, R. (Eds.), Handbook of Industrial Organization. Vol. 3. North-Holland, Amsterdam.

Tirole, J., 1988. The theory of industrial organization. MIT press, Cambridge, MA.

van der Weijde, A. H., Verhoef, E. T., van den Berg, V. A. C., 2013. Competition in multi-modal transport networks: a dynamic approach. Transportation Research Part B: Methodological 53, $31-44$.

Verboven, F., 2008. Price discrimination (empirical studies). In: Durlauf, S. N., Blume, L. E. (Eds.), The New Palgrave Dictionary of Economics. Palgrave Macmillan, Basingstoke.

Verhoef, E. T., Nijkamp, P., Rietveld, P., 1995. Second-best regulation of road transport externalities. Journal of Transport Economics and Policy 29, 147-167.

Zhang, A., Czerny, A. I., 2012. Airports and airlines economics and policy: an interpretive review. Economics of Transportation 1 (1), 15-34.

\section{Appendix - output effects in a model with two serial links}

\section{Symmetric model}

Define $\phi \equiv 2 f_{s}-f_{l}$, and direct, link-based demand $N\left(f_{s}, 2 f_{s}-\phi\right) \equiv N_{s}+N_{l}$. Then,

$$
\begin{aligned}
\frac{d N}{d \phi} & =\frac{\partial N}{\partial f_{s}} \frac{d f_{s}}{d \phi}+\frac{\partial N}{\partial f_{l}} \frac{d f_{l}}{d \phi} \\
& =\frac{d f_{s}}{d \phi}\left(\frac{\partial N}{\partial f_{s}}+2 \frac{\partial N}{\partial f_{l}}\right)-\frac{\partial N}{\partial f_{l}}
\end{aligned}
$$

Totally differentiating the two user equilibrium conditions and applying Cramer's Rule gives 


$$
\begin{aligned}
& \frac{\partial N_{s}}{\partial f_{s}}=\left(D_{l}^{\prime}-2 \alpha \beta c^{\prime}\right) / \Omega \\
& \frac{\partial N_{l}}{\partial f_{s}}=2 \alpha c^{\prime} / \Omega \\
& \frac{\partial N_{s}}{\partial f_{l}}=\beta c^{\prime} / \Omega \\
& \frac{\partial N_{l}}{\partial f_{l}}=\left(D_{s}^{\prime}-c^{\prime}\right) / \Omega
\end{aligned}
$$

where $\Omega \equiv\left|\begin{array}{cc}D_{s}^{\prime}-c^{\prime} & -\beta c^{\prime} \\ -2 \alpha c^{\prime} & D_{l}^{\prime}-2 \alpha \beta c^{\prime}\end{array}\right|>0$

Hence,

$$
\begin{aligned}
& \frac{\partial N}{\partial f_{s}}=\left(D_{l}^{\prime}-2 \alpha(\beta-1) c^{\prime}\right) / \Omega \\
& \frac{\partial N}{\partial f_{l}}=\left(D_{s}^{\prime}+(\beta-1) c^{\prime}\right) / \Omega
\end{aligned}
$$

Finally,

$$
\begin{gathered}
\pi\left(f_{s}\right)=2 f_{s} N_{s}\left(f_{s}, 2 f_{s}-\phi\right)+\left(2 f_{s}-\phi\right) N_{l}\left(f_{s}, 2 f_{s}-\phi\right) \\
\pi^{\prime}=2 N+2 f_{s}\left(\frac{\partial N}{\partial f_{s}}+2 \frac{\partial N}{\partial f_{l}}\right)-\phi\left(\frac{\partial N_{l}}{\partial f_{s}}+2 \frac{\partial N_{l}}{\partial f_{l}}\right)
\end{gathered}
$$

Treating $\phi$ as exogenous and totally differentiating this first-order condition with respect to $\phi$ gives

$$
\frac{\partial f_{s}}{\partial \phi}=-\frac{\partial^{2} \pi /\left(\partial \phi \partial f_{s}\right)}{\partial^{2} \pi /\left(\partial f_{s}\right)^{2}}
$$

where

$$
\begin{aligned}
\partial^{2} \pi /\left(\partial \phi \partial f_{s}\right) & =2 \frac{\partial N}{\partial \phi}-\frac{\partial N_{l}}{\partial f_{s}}-2 \frac{\partial N_{l}}{\partial f_{l}}+2 f_{s}\left(\frac{\partial^{2} N}{\partial \phi \partial f_{s}}+2 \frac{\partial^{2} N}{\partial \phi \partial f_{l}}\right)-\phi\left(\frac{\partial^{2} N_{l}}{\partial \phi \partial f_{s}}+2 \frac{\partial^{2} N_{l}}{\partial \phi \partial f_{l}}\right) \\
& =-2 \frac{\partial N}{\partial f_{l}}-\frac{\partial N_{l}}{\partial f_{s}}-2 \frac{\partial N_{l}}{\partial f_{l}}-2 f_{s}\left(\frac{\partial^{2} N}{\partial f_{l} \partial f_{s}}+2 \frac{\partial^{2} N}{\left(\partial f_{l}\right)^{2}}\right)+\phi\left(\frac{\partial^{2} N_{l}}{\partial f_{l} \partial f_{s}}+2 \frac{\partial^{2} N_{l}}{\left(\partial f_{l}\right)^{2}}\right)
\end{aligned}
$$

and

$$
\partial^{2} \pi /\left(\partial f_{s}\right)^{2}=4 \frac{\partial N}{\partial f_{s}}+8 \frac{\partial N}{\partial f_{l}}+2 f_{s}\left(\frac{\partial^{2} N}{\left(\partial f_{s}\right)^{2}}+2 \frac{\partial^{2} N}{\partial f_{s} \partial f_{l}}\right)-\phi\left(\frac{\partial^{2} N_{l}}{\left(\partial f_{s}\right)^{2}}+2 \frac{\partial^{2} N_{l}}{\partial f_{s} \partial f_{l}}\right)
$$

If demand- and cost functions are linear, 


$$
\begin{aligned}
& \frac{\partial f_{s}}{\partial \phi}=\frac{2 D_{s}^{\prime}+(\alpha+\beta-2) c^{\prime}}{2\left(D_{l}^{\prime}+D_{s}^{\prime}-(2 \alpha-1)(\beta-1) c^{\prime}\right)} \\
& \frac{d N}{d \phi}=\frac{1}{\Omega}\left[\frac{\left(2 D_{s}^{\prime}+(\alpha+\beta-2) c^{\prime}\right)\left(D_{l}^{\prime}+2 D_{s}^{\prime}-2(\alpha-1)(\beta-1) c^{\prime}\right)}{2\left(D_{l}^{\prime}+D_{s}^{\prime}-(2 \alpha-1)(\beta-1) c^{\prime}\right)}-\left(D_{s}^{\prime}+(\beta-1) c^{\prime}\right)\right] \\
& \frac{d N}{d \phi}=\frac{(\alpha-\beta) c^{\prime}}{2 \Omega}
\end{aligned}
$$

\section{General model}

In a more general model, with three inverse demand functions $D_{12}\left(N_{12}\right), D_{23}\left(N_{23}\right), D_{13}\left(N_{13}\right)$, and cost functions $c_{12}$ and $c_{23}$ for the short-distance travelers, and $\alpha\left(c_{12}+c_{23}\right)$ for the long-distance travelers, it can be shown, in exactly the same way, that the output effect of an increase in $\phi$ is still zero if $\alpha=\beta$.

In this case, there are three fares, and the price difference $\phi$ can be written as

$$
\phi \equiv f_{12}+f_{23}-f_{13} \Longleftrightarrow f_{13}=f_{12}+f_{23}-\phi
$$

and there link-based total direct demand functions are given by

$$
\begin{aligned}
& N_{1}\left(f_{12}, f_{23}, f_{12}+f_{23}-\phi\right) \equiv N_{12}+N_{13} \\
& N_{2}\left(f_{12}, f_{23}, f_{12}+f_{23}-\phi\right) \equiv N_{23}+N_{13}
\end{aligned}
$$

The impact of price differentiation on the usage level of first link can then be written as

$$
\begin{aligned}
\frac{d N_{1}}{d \phi} & =\frac{\partial N_{1}}{\partial f_{12}} \frac{d f_{12}}{d \phi}+\frac{\partial N_{1}}{\partial f_{23}} \frac{d f_{23}}{d \phi}+\frac{\partial N_{1}}{\partial f_{13}} \frac{d f_{13}}{d \phi} \\
& =\frac{\partial N_{1}}{\partial f_{12}} \frac{d f_{12}}{d \phi}+\frac{\partial N_{1}}{\partial f_{23}} \frac{d f_{23}}{d \phi}+\frac{\partial N_{1}}{\partial f_{13}}\left(\frac{d f_{12}}{d \phi}+\frac{d f_{23}}{d \phi}-1\right) \\
& =\left(\frac{\partial N_{1}}{\partial f_{12}}+\frac{\partial N_{1}}{\partial f_{13}}\right) \frac{d f_{12}}{d \phi}+\left(\frac{\partial N_{1}}{\partial f_{23}}+\frac{\partial N_{1}}{\partial f_{13}}\right) \frac{d f_{23}}{d \phi}-\frac{\partial N_{1}}{\partial f_{13}}
\end{aligned}
$$

In this case, there are three user equilibrium conditions. Totally differentiating those, and using Cramer's Rule gives: 


$$
\begin{aligned}
\frac{\partial N_{12}}{\partial f_{12}} & =\left(\left(D_{23}^{\prime}-c_{23}^{\prime}\right)\left(D_{13}^{\prime}-\alpha \beta c_{12}^{\prime}-\alpha \beta c_{23}^{\prime}\right)-\alpha \beta c_{23}^{\prime 2}\right) / \Omega<0 \\
\frac{\partial N_{23}}{\partial f_{12}} & =\alpha \beta c_{12}^{\prime} c_{23}^{\prime} / \Omega<0 \\
\frac{\partial N_{13}}{\partial f_{12}} & =\left(D_{23}^{\prime}-c_{23}^{\prime}\right)\left(\alpha c_{12}^{\prime}\right) / \Omega>0 \\
\frac{\partial N_{12}}{\partial f_{23}} & =\alpha \beta c_{12}^{\prime} c_{23}^{\prime} / \Omega<0 \\
\frac{\partial N_{23}}{\partial f_{23}} & =\left(\left(D_{12}^{\prime}-c_{12}^{\prime}\right)\left(D_{13}^{\prime}-\alpha \beta c_{12}^{\prime}-\alpha \beta c_{23}^{\prime}\right)-\alpha \beta c_{12}^{\prime 2}\right) / \Omega<0 \\
\frac{\partial N_{13}}{\partial f_{23}} & =\left(D_{12}^{\prime}-c_{12}^{\prime}\right)\left(\alpha c_{23}^{\prime}\right) / \Omega>0 \\
\frac{\partial N_{12}}{\partial f_{13}} & =\left(D_{23}^{\prime}-c_{23}^{\prime}\right)\left(\beta c_{12}^{\prime}\right) / \Omega>0 \\
\frac{\partial N_{23}}{\partial f_{13}} & =\left(D_{12}^{\prime}-c_{12}^{\prime}\right)\left(\beta c_{23}^{\prime}\right) / \Omega>0 \\
\frac{\partial N_{13}}{\partial f_{13}} & =\left(D_{12}^{\prime}-c_{12}^{\prime}\right)\left(D_{23}^{\prime}-c_{23}^{\prime}\right) / \Omega<0 \\
D_{12}^{\prime}-c_{12}^{\prime} & 0 \\
0 & D_{23}^{\prime}-c_{23}^{\prime} \quad-\beta c_{12}^{\prime} \\
-\alpha c_{12}^{\prime} & -\alpha c_{23}^{\prime} \quad D_{13}^{\prime}-\alpha \beta\left(c_{12}^{\prime}+c_{23}^{\prime}\right)
\end{aligned} \mid<0
$$

Finally, the first-order conditions for profit maximization can be written as

$$
\begin{aligned}
& \frac{\partial \pi}{\partial f_{12}}=N_{1}+f_{12}\left(\frac{\partial N_{1}}{\partial f_{12}}+\frac{\partial N_{1}}{\partial f_{13}}\right)+f_{23}\left(\frac{\partial N_{2}}{\partial f_{12}}+\frac{\partial N_{2}}{\partial f_{13}}\right)-\phi\left(\frac{\partial N_{13}}{\partial f_{12}}+\frac{\partial N_{13}}{\partial f_{13}}\right)=0 \\
& \frac{\partial \pi}{\partial f_{23}}=N_{2}+f_{12}\left(\frac{\partial N_{1}}{\partial f_{23}}+\frac{\partial N_{1}}{\partial f_{13}}\right)+f_{23}\left(\frac{\partial N_{2}}{\partial f_{23}}+\frac{\partial N_{2}}{\partial f_{13}}\right)-\phi\left(\frac{\partial N_{13}}{\partial f_{23}}+\frac{\partial N_{13}}{\partial f_{13}}\right)=0
\end{aligned}
$$

treating $\phi$ as exogenous and totally differentiating these first-order conditions gives

$$
\begin{aligned}
\frac{d}{d \phi} \frac{\partial \pi}{\partial f_{12}} & =\frac{\partial^{2} \pi}{\left(\partial f_{12}\right)^{2}} \frac{d f_{12}}{d \phi}+\frac{\partial^{2} \pi}{\partial f_{23} \partial f_{12}} \frac{d f_{23}}{d \phi}+\frac{\partial^{2} \pi}{\partial \phi \partial f_{12}}=0 \\
\frac{d}{d \phi} \frac{\partial \pi}{\partial f_{23}} & =\frac{\partial^{2} \pi}{\partial f_{12} \partial f_{23}} \frac{d f_{12}}{d \phi}+\frac{\partial^{2} \pi}{\left(\partial f_{23}\right)^{2}} \frac{d f_{23}}{d \phi}+\frac{\partial^{2} \pi}{\partial \phi \partial f_{23}}=0
\end{aligned}
$$

Using Cramer's Rule:

$$
\frac{d f_{12}}{d \phi}=\left|\begin{array}{cc}
-\frac{\partial^{2} \pi}{\partial \phi \partial f_{12}} & \frac{\partial^{2} \pi}{\partial f_{23} \partial f_{12}} \\
-\frac{\partial^{2} \pi}{\partial \phi \partial f_{23}} & \frac{\partial^{2} \pi}{\left(\partial f_{23}\right)^{2}}
\end{array}\right| /|H|, \frac{d f_{23}}{d \phi}=\left|\begin{array}{cc}
\frac{\partial^{2} \pi}{\left(\partial f_{12}\right)^{2}} & -\frac{\partial^{2} \pi}{\partial \phi \partial f_{12}} \\
\frac{\partial^{2} \pi}{\partial f_{12} \partial f_{23}} & -\frac{\partial^{2} \pi}{\partial \phi \partial f_{23}}
\end{array}\right| /|H|
$$


where $H$ is the Hessian of $\pi$ :

$$
|H|=\left|\begin{array}{cc}
\frac{\partial^{2} \pi}{\left.\partial f_{12}\right)^{2}} & \frac{\partial^{2} \pi}{\partial f_{23} \partial f_{12}} \\
\frac{\partial^{2} \pi}{\partial f_{12} \partial f_{23}} & \frac{\partial^{2} \pi}{\left(\partial f_{23}\right)^{2}}
\end{array}\right|=\frac{\partial^{2} \pi}{\left(\partial f_{12}\right)^{2}} \frac{\partial^{2} \pi}{\left(\partial f_{23}\right)^{2}}-\left(\frac{\partial^{2} \pi}{\partial f_{12} \partial f_{23}}\right)^{2}
$$

If demand- and cost functions are linear,

$$
\begin{aligned}
\frac{\partial^{2} \pi}{\partial \phi \partial f_{12}} & =-\left(\frac{\partial N_{1}}{\partial f_{13}}+\frac{\partial N_{13}}{\partial f_{12}}+\frac{\partial N_{13}}{\partial f_{13}}\right) \\
\frac{\partial^{2} \pi}{\partial \phi \partial f_{23}} & =-\left(\frac{\partial N_{2}}{\partial f_{13}}+\frac{\partial N_{13}}{\partial f_{23}}+\frac{\partial N_{13}}{\partial f_{13}}\right) \\
\frac{\partial^{2} \pi}{\left(\partial f_{12}\right)^{2}} & =2\left(\frac{\partial N_{1}}{\partial f_{12}}+\frac{\partial N_{1}}{\partial f_{13}}\right) \\
\frac{\partial^{2} \pi}{\partial f_{23} \partial f_{12}} & =\frac{\partial N_{1}}{\partial f_{23}}+\frac{\partial N_{1}}{\partial f_{13}}+\frac{\partial N_{2}}{\partial f_{12}}+\frac{\partial N_{2}}{\partial f_{13}} \\
\frac{\partial^{2} \pi}{\left(\partial f_{23}\right)^{2}} & =2\left(\frac{\partial N_{2}}{\partial f_{23}}+\frac{\partial N_{2}}{\partial f_{13}}\right)
\end{aligned}
$$

These expressions can be substituted in $\partial f_{12} / \partial \phi$ and $\partial f_{23} / \partial \phi$, and the result combined with the partial derivatives of the usage levels with respect to the fares and the expression for $d N_{1} / d \phi$ given above. This straightforward substitution exercise is too tedious even for this appendix, and the resulting expression is too long to print here. It is, however, equal to zero when $\alpha=\beta$. 